\title{
LAS NARRATIVAS DE LA BIOTECNOLOGÍA
}

\section{THE NARRATIVES OF BIOTECHNOLOGY}

\author{
MANUEL JESÚS LÓPEZ BARONI \\ mjbaroni1@upo.es \\ Universidad Pablo de Olavide
}

RECIBIDO: $10 / 03 / 2018$

ACEPTADO: 18/07/2018

\begin{abstract}
Resumen: Sobre la biotecnología se proyectan ideologías, prejuicios, expectativas y temores que nada tienen que ver con la ciencia y sí por el contrario con la naturaleza humana. Además, la confluencia entre esta disciplina y las denominadas tecnologías disruptivas desdibuja aún más su contenido. Pues bien, con objeto de deslindar nítidamente los aspectos puramente científicos de los culturales e ideológicos, incluido el esoterismo, hemos construido un modelo con dos variables y cuatro combinaciones posibles. Estimamos que el análisis de las diferentes narrativas que receptan la biotecnología contribuirá a clarificar los retos que presenta esta materia.
\end{abstract}

Palabras clave: Biotecnología; transgénico; organismo modificado genéticamente; tecnologías disruptivas; tecnologías de la sospecha.

\begin{abstract}
About biotechnology are projected ideologies, prejudices, expectations and fears that have nothing to do with science and, on the contrary, with human nature. In addition, the confluence between biotechnology and the so-called disruptive technologies further blurs its content. Well, in order to clearly define the purely scientific aspects of cultural and ideological aspects, including esotericism, we have constructed a model with two variables and four possible combinations. We believe that the analysis of the different narratives that receive biotechnology will help to clarify the challenges presented by this discipline.
\end{abstract}

Keywords: Biotechnology; transgenic; genetically modified organism; disruptive technologies; suspicion technologies.

\section{Introducción}

La biotecnología es una disciplina prácticamente inabarcable, que tiene por objeto materias tan dispares como la energía, la agricultura o la biomedicina de última generación. A la vez, sus temáticas tradicionales están siendo flanqueadas por investigaciones que rozan la ciencia ficción, como las relacionadas con la vida sintética y la inteligencia artificial. En esencia, la interacción entre la biotecnología, las ciencias cognitivas, los big data y la informática auguran un futuro prometedor, en lo que a reflexión (y preocupación) se refiere. 
Pues bien, precisamente por la existencia de relaciones transversales entre campos del conocimiento tan lejanos entre sí, resulta difícil analizar de una forma coherente y sistemática las cuestiones que suscita la biotecnología. Por ello, nos conformaremos con presentar una fractal de la situación actual. El punto de fricción sobre el que nos vamos a centrar es en el cruce entre la biotecnología y las ciencias sociales.

En efecto, sobre la biotecnología se proyectan ideologías, prejuicios, expectativas y temores que nada tienen que ver con la ciencia y sí por el contrario con la naturaleza humana. Entre estas proyecciones se sitúan dicotomías o tricotomías como marxismo/neoliberalismo; patriarcado/ feminismo; globalización/ multiculturalismo; tecnoutopismo/milenarismo; laicismo/panteísmo/monoteísmo, etc. La confluencia entre los aspectos puramente científicos de la biotecnología, esto es, los elementos endógenos y propios de la disciplina, y los factores exógenos que hemos citado, de naturaleza cultural e ideológica, provoca que la complejidad desemboque con facilidad en la perplejidad.

Pues bien, las preguntas que vamos a abordar, que no es lo mismo que resolver, son las siguientes.

a) ¿Es legítima la biotecnología en sí misma? Una de las paradojas de la disciplina que analizamos es que, mientras nadie discute la moralidad de la medicina, la química o la física, en el caso que analizamos se ha invertido la presunción de inocencia y los biotecnólogos han de argumentar constantemente por qué su mera existencia no constituye una afrenta contra la humanidad. Estimamos que desarbolar esta imputación, equivalente epistemológico del racismo, contribuirá, con las clarificaciones pertinentes, a la defensa de este colectivo.

b) ¿Cuándo comenzó la biotecnología a ser un problema? La cuestión en este caso no reside en mostrar cuándo apareció la biotecnología moderna, soporífera temática que suele desembocar en el esencialismo, sino a partir de qué momento las ciencias sociales y las humanidades se percataron de que la biotecnología contemporánea arrostraba dilemas tan perturbadores como desasosegantes.

c) ¿Cuándo es ético modificar la naturaleza? Partiendo de la premisa de que toda especie viva, incluida la humana, interfiere con su entorno, la cuestión es reflexionar sobre a partir de qué momento deja de ser esta observación participante legítima y comienza a ser una agresión contra natura.

d) ¿Cuál es el criterio de demarcación de lo ecológico? En este caso nos planteamos en qué momento un discurso, actuación, programa o paradigma deja 
de ser ecologista, arquetipo de la moralidad neokantiana, y se convierte en nefando crimen de ecocidio.

e) ¿Cuál es el criterio de demarcación de lo transgénico? Aunque a priori parece que es una distinción obvia, el análisis de las definiciones que nos ofrecen los diferentes expertos nos sume con facilidad, por su insuficiencia, en la más absoluta pesadumbre. Como veremos, no resulta nada sencillo hallar criterios verificables e indubitados que diferencien con la suficiente nitidez un organismo modificado genéticamente de un transgénico, y a su vez, estas dos categorías del resto de seres vivos.

h) ¿Debemos juridificar la ciencia ficción? El problema que nos planteamos con esta cuestión es si la bioética y el derecho deben intervenir ante escenarios improbables pero no imposibles, o, por plantearlo de otra forma, cuál es el momento adecuado para actuar. Si se hace muy pronto, se corre el riesgo de regular predicciones fantásticas, deslizándonos sin remisión alguna por la pendiente del ridículo; pero si esperamos, entre dubitativos y contemplativos, a la política de hechos consumados, puede que sea demasiado tarde para escenarios hipotéticos pero no fantasiosos en los que está en juego la existencia de la vida misma.

I) ¿Es suficiente la autorregulación científica? El principal instrumento que emplea la comunidad investigadora para prevenir resultados imprevisibles es la moratoria científica. Ahora bien, ¿nos basta con su sentido común, prudencia, humanidad, etc., en contextos donde se movilizan ingentes sumas de dinero? ¿Acaso los científicos no son susceptibles de ser infectados por el humano virus de la ambición, el poder o la megalomanía? Y por último, dado que es un colectivo sometido a un especial estrés por la demanda social para que sean competitivos, innovadores, etc., e incluso, como si no fuera bastante, hasta emprendedores y generadores de empleo, ¿realmente podemos pedirles más? ¿Acaso no nos conduciría a una temeraria delegación de nuestra responsabilidad simplemente porque no nos esforzamos lo suficiente en comprender el alcance de sus investigaciones?

Pues bien, con objeto de clarificar estas cuestiones, a menudo enmarañadas con discursos tan enrevesados como inconsistentes, hemos creado un modelo con dos variables y cuatro combinaciones posibles. En este caso, las dos variables son "biotecnología tradicional" (la forma de intervención del ser humano en la naturaleza desde nuestros orígenes) y "biotecnología moderna" (las 
técnicas, recursos y objetivos de la biotecnología contemporánea). Dado que hay dos variables, las combinaciones son cuatro, que resumimos a continuación: ${ }^{1}$

Primera combinación: Biotecnología tradicional (0); Biotecnología moderna (0). En este paradigma situaremos los discursos de quienes sostienen que no hay ruptura ni hiato entre lo que los seres humanos hemos estado haciendo durante miles de años y la época actual. Son las narrativas de la continuidad, que abogan por no alarmar a la población ni a las autoridades públicas. El grafismo 0-0 reflejaría esta ausencia de hiatos entre el pasado y el presente.

Segunda combinación: Biotecnología tradicional (1); Biotecnología moderna (1). En este paradigma situaremos los discursos de quienes argumentan que la biotecnología moderna es cualitativamente diferente a la de épocas pretéritas, pero que basta con el principio de precaución para avanzar con seguridad. El grafismo 1-1 refleja la idea de que, aunque ambas formas de biotecnología son relevantes, existe un hiato nítido y sustancial entre ambas.

Tercera combinación: Biotecnología tradicional (1); Biotecnología moderna (0). En este paradigma situaremos los discursos de quienes sostienen que la biotecnología moderna cosifica a los seres vivos y legitima el capitalismo neoliberal, por lo que es una disciplina inmoral en sí misma. El grafismo 1-0 refleja la idea de que solo son legítimas las técnicas tradicionales de intervención en la naturaleza (selección y cruce), de ahí que aboguen por prohibir cualquier forma de biotecnología moderna.

Cuarta combinación: Biotecnología tradicional (0); Biotecnología moderna (1). En este paradigma situaremos los discursos que sostienen que lo mejor (o peor) está por llegar, lo que incluye tanto las narrativas tecnoutópicas, que estiman que la tecnología resolverá la cuestión humana, como las predicciones apocalípticas y distópicas que advierten sobre la pronta extinción de la especie humana e incluso de la vida misma.

Cada uno de estas cuatro combinaciones conlleva axiomas o puntos de partida que juegan el papel de actos de fe apriorísticos; un vocabulario específico compuesto de expresiones, ideas o conceptos cuyo significado varía de paradigma en paradigma (v. gr., qué es un transgénico); una definición sui generis de la biotecnología; preguntas solo comprensibles dentro de un paradigma; funciones y principios específicos de la bioética; y, por último, anomalías, es decir, contradicciones o cuestiones irresueltas.

\footnotetext{
${ }^{1}$ Empleamos un modelo análogo al empleado por Gustavo Bueno en ¿Qué es la ciencia? y por Castilla del Pino en su Teoría de los Sentimientos.
} 
Estimamos que esta forma de analizar brevemente la situación de la biotecnología clarificará las diferentes narrativas que abordan esta disciplina, clarificación imprescindible para la toma de decisiones.

\section{Primer modelo: "biotecnología tradicional (0)"; "biotecnología moderna" (0)"}

Los axiomas básicos de las narrativas pertenecientes a este paradigma son los siguientes:

$\left.1^{\circ}\right)$ No hay una diferencia cualitativa entre lo que hacían los primeros agricultores y la ingeniería genética contemporánea.

$2^{\circ}$ ) No resulta necesario crear principios específicos de la bioética para resolver los problemas que se presenten, bastando para ello con los cuatro tradicionales. Además, estos solo serán aplicables para las cuestiones que se susciten en biomedicina, pero no en otros campos, como la agricultura, la energía, etc.

$3^{\circ}$ ) No hay diferencias sustanciales entre los organismos modificados genéticamente y los transgénicos, de un lado, y el resto de seres vivos, de otro.

$\left.4^{\circ}\right)$ La diferencia entre organismos naturales y artificiales (v. gr. entre el maíz natural y el maíz transgénico) es de naturaleza metafísica.

La historia del origen del maíz y del perro son dos buenos ejemplos para comprender la justificación de estos cuatro axiomas.

Hasta los años ochenta del siglo pasado hubo un enconado debate acerca del origen del maíz. ${ }^{2}$ Reeves y Mangelsdorf defendían que el maíz contemporáneo descendía de un maíz ancestral, probablemente ya extinto, el maíz tunicado, lo que favorecía indirectamente los argumentos a favor de la existencia de una continuidad entre ambos tipos de maíz y, por tanto, que esa modificación no fue un proceso tan difícil ni tan artificial.

Sin embargo, en tiempos recientes se ha demostrado que el maíz contemporáneo procede de una especie de las gramíneas denominada "teosinte" que existía en México y en Mesoamérica. ${ }^{3}$ Hace unos ocho mil años, los habitantes de esas tierras procedieron a un laborioso, ingenioso e intuitivo método de cruzamiento mediante selección hasta lograr que una planta con solo dos hileras de granos, escasamente nutritivos, se convirtiese en el maíz que alimenta hoy a millones de personas.

\footnotetext{
${ }^{2}$ BEADLE, George: "El origen del maíz”, Investigación y Ciencia, nº 42, marzo, 1980.

${ }^{3}$ KATO YAMAKAKE, Takeo Ángel: “¿Cómo y dónde se originó el maíz?” Investigación y Ciencia, $n^{\circ} 347,2005$.
} 
Este dato nos demuestra que el maíz contemporáneo no es un alimento natural, esto es, generado azarosamente por la naturaleza, sino que es una creación estrictamente humana. El maíz no solo existe porque los seres humanos lo hayan creado, sino que sin los seres humanos desaparecería, ya que si no se recogen los granos estos caerían demasiado cerca de la mazorca, con lo que no madurarían. ${ }^{4}$

El segundo dato relevante para nuestro estudio es que el maíz es la consecuencia de la expresión de cinco genes del teosinte. ${ }^{5,6}$ Los indígenas lograron, aun sin saber qué son los genes, la modificación genética del teosinte. En puridad, el maíz natural contemporáneo sería un organismo modificado genéticamente, en concreto, el teosinte.

Estos datos son los que vertebran discursos como el de la catedrática Capell Capell, ante el parlamento español, que sostienen que "El maíz es una planta totalmente artificial, no existía; es una planta que ha sido fruto de la tecnología humana". 7

De forma análoga a lo que ha sucedido con el maíz, también se ha discutido durante bastante tiempo el origen del perro. Los estudios más recientes indican que el perro actual no procede del lobo contemporáneo, sino de un lobo ancestral, ya extinto, del que proceden ambos, los perros y los lobos que conocemos hoy día.

Para nuestro objeto de estudio, lo relevante es que el perro también es una creación humana, ya que nunca existió en estado salvaje en la naturaleza. Aunque es un misterio cómo se produjo la transición entre el lobo ancestral y el perro, se sabe que los seres humanos lograron en dos ocasiones, en Asia y en Europa, mediante técnicas de cruzamiento y domesticación, que estos surgieran ex novo en la naturaleza. Además, quienes lo consiguieron eran cazadores recolectores, y no agricultores, ya que el espectro de fechas varía entre los 18.000 y los 32.000 años a.C., bastante antes de que apareciera la agricultura, con lo que resulta razonable vincular la domesticación del lobo a las necesidades de la caza. ${ }^{8,9,10,11}$

\footnotetext{
${ }^{4}$ MANGELSDORF, Paul: "El origen del maíz”, Investigación y Ciencia, 121, Octubre, 1986.

${ }^{5}$ KATO, Op. cit.

${ }^{6}$ SERRATOS HERNÁNDEZ: El origen y la diversidad del maíz en el continente americano, Greenpeace, 2009.

${ }^{7}$ CAPELL CAPELL, (2013): Catedrática del Departamento de Producción Vegetal y Ciencia Forestal de la Universidad de Lleida, e investigadora de agrotecnio. Diario de Sesiones del Congreso de los Diputados. Comisiones. Núm. 460, 19 de noviembre, p. 13.

${ }^{8}$ VILÁ, Carles: "Domesticación del perro. Relaciones entre perro y lobo", Investigación y Ciencia, marzo, 1999.

${ }^{9}$ MORELL, Virginia: “Evolución del lobo al perro”, Investigación y Ciencia. Septiembre, 2015.
} 
Si caminamos por nuestros parques, plazas y calles, observaremos infinidad de razas de perro. La reflexión que debemos hacer es la siguiente: la naturaleza no produce cosas como los caniches, los perros salchicha, o los chuchos mismos, porque se los hubiesen comido. Es más, sin nosotros, los perros desaparecerían de la faz de la tierra, ya que no están evolutivamente adaptados a valerse por sí mismos. Quizá los perros salvajes sí hayan aprendido a sobrevivir, pero la inmensa mayoría de las razas que conocemos estaría condenada a la extinción.

Desde esta perspectiva, el perro, como el maíz, y al igual que sucede con la inmensa mayoría de las frutas y hortalizas, es tan artificial como los ordenadores. Han sido creados por los seres humanos, y no por la naturaleza. Hemos sido nosotros, aun desconociendo qué eran, no ya los genes, sino las células mismas, quienes hemos modificado inconscientemente la dotación genética de determinados seres vivos ancestrales (el teosinte, el lobo, etc.) hasta lograr la aparición de seres vivos artificiales. ${ }^{12}$

Por ello, quienes se guarecen bajo la narrativa de este primer paradigma sostienen que la división dialéctica clásica entre lo natural y lo artificial, o entre lo natural y lo cultural, es pura retórica, una distinción metafísica. La mera existencia humana conlleva una intervención en la naturaleza, una modificación, alteración y recreación para adaptarla a nuestras necesidades, al igual que sucede, por cierto, con el resto de seres vivos. Basta recordar cómo, en su momento, un determinado tipo de bacteria produjo como desecho el oxígeno que ha permitido la vida compleja, incluida la nuestra.

Por ello, todos los discursos acerca de la vuelta a los orígenes, el agroecologismo, la comida natural, ecológica, orgánica, etc., serían pura mistificación, y quienes defienden estos conceptos estarían empleando expresiones análogas a los teólogos con la santísima trinidad. La defensa de un mundo prístino, sin intervención humana, donde el ser humano toma de la madre

${ }^{10}$ LAURENT, A. F. Frantz, Victoria E. Mullin, Maud Pionnier-Capitan, Ophélie Lebrasseur, Morgane Ollivier, Angela Perri, Anna Linderholm, Valeria Mattiangeli, Matthew D. Teasdale, Evangelos A. Dimopoulos, Anne Tresset, Marilyne Duffraisse, Finbar McCormick, László Bartosiewicz, Erika Gál, Éva A. Nyerges, Mikhail V. Sablin, Stéphanie Bréhard, Marjan Mashkour, Adrian Bălăşescu, Benjamin Gillet, Sandrine Hughes, Olivier Chassaing, Christophe Hitte, JeanDenis Vigne, Keith Dobney, Catherine Hänni, Daniel G. Bradley, Greger Larson, (2016): "Genomic and archaeological evidence suggest a dual origin of domestic dogs", Science, 03 Jun, 2016. Pp. 1228-1231.

${ }^{11}$ FREEDMAN, AH, Gronau I, Schweizer RM, Ortega-Del Vecchyo D, Han E, Silva PM, et al: "Genome Sequencing Highlights the Dynamic Early History of Dogs." PLoS Genet 10(1), 2014.

${ }^{12}$ La posibilidad de domesticar los zorros para que se conviertan en animales domésticos como los perros ahondarían en este proceso de modificación intencionada de la naturaleza. TRUT, Lyudmila\&DUGATKIN, Lee Alan: "Zorros convertidos en perros". Investigación y Ciencia, n' 490, julio de 2017. 
tierra lo que necesita, y no más, sin alterarla ni contaminarla, sería el equivalente al paraíso perdido judeocristiano, donde la biotecnología jugaría el papel que tuvo la manzana que mordió Eva.

Teniendo esto presente, podemos comprender la definición de la biotecnología que aparece en la Enciclopedia Británica: "La utilización de la biología para resolver problemas y hacer productos útiles".

De la infinidad de definiciones que podemos rastrear en libros y documentos es la más sencilla, ya que rompe con la dicotomía biotecnología tradicional versus biotecnología contemporánea. Lo que hacían nuestros antepasados es lo mismo que hacen los científicos actuales en un laboratorio: modificar la dotación genética de los seres vivos ("utilizar la biología") para adaptarlos a nuestras necesidades ("resolver problemas") y emplearlos como fuentes de alimentación, energía o modelos humanos ("productos útiles").

Esta definición justifica que la bioética no deba intervenir en la biotecnología. A no ser que se planteen cuestiones específicas en biomedicina, donde bastará con el arsenal de los cuatro principios de la bioética, en el resto de materias (agricultura, seres vivos no humanos, energía, medio ambiente, vida artificial, etc.) no resulta legítima la intervención, dado que la participación de un bioeticista sería tan anómala como su presencia en el consejo de administración de un banco.

La no intervención de la bioética se justificaría además porque no existe propiamente una diferencia sustancial entre los organismos genéticamente modificados y el resto de los seres vivos. Si no hay diferencias entre la agricultura tradicional y la biotecnología moderna, ¿por qué iban a existir los transgénicos?

El mejor ejemplo de este modelo lo podemos observar en el Departamento de Agricultura de Estados Unidos (USDA), que no distingue entre las técnicas tradicionales de cruzamiento y la ingeniería genética contemporánea. ${ }^{13}$ Es más,

\footnotetext{
${ }^{13}$ Así, se puede observar esta mezcla entre agricultura tradicional y biotecnología moderna en la página web de USDA, UNITED STATES DEPARTMENT OF AGRICULTURE "Agricultural Biotechnology: A range of tools, including breeding techniques, (...) Genetic modification: The production of heritable improvement in plants or animals for specific uses, via either genetic engineering or other more traditional methods. Some countries other than the United States use this term to refer specifically to genetic engineering. (...) Transgenic organism: An organism resulting from the insertion of genetic material from another organism using recombinant DNA techniques: (...) Traditional breeding: Modification of plants and animals through selective breeding. Practice used in traditional plant breeding may include aspects of biotechnology such as tissue culture and mutational breeding"

En https://www.usda.gov/topics/biotechnology/biotechnology-glossary. Última visita en febrero de 2018.
} 
reconocen expresamente que su definición de "organismo genéticamente modificado" no es equivalente a la de la Unión Europea, que como analizaremos en el siguiente modelo sí distingue entre estos organismos y el resto de seres vivos.

La consecuencia práctica de este batiburrillo conceptual, o monismo ("todo es lo mismo"), la podemos constatar en lo que recién ha sucedido con un determinado tipo de champiñón. Empleando la novedosa técnica de ingeniería genética CRISPR, un grupo de científicos ha silenciado un grupo de genes en un champiñón natural, logrando con ello que conserve su color original más tiempo. Cuando estos científicos preguntaron al Departamento de Agricultura norteamericano si se le aplicaría a este champiñón la legislación vigente para los transgénicos, la respuesta oficial fue que no hacía falta, ya que no se estaba ante un transgénico (Hall, 2016).

$\mathrm{Si}$ generalizamos este suceso, podemos prever que cualquier ser vivo que sea modificado con la técnica CRISPR no será considerado un organismo modificado genéticamente ni un transgénico, con lo que pasará del laboratorio a la cadena alimenticia directamente, al igual que sucede con la fruta u hortaliza lograda con las técnicas tradicionales de cruzamiento. La Unión Europea está pendiente de pronunciarse sobre esta temática, pero cabe augurar que no seguirá el trazo grueso de sus homólogos norteamericanos.

¿Cuáles son las anomalías que podemos observar en el paradigma que analizamos?

Examinemos uno de los bioeslóganes propagandísticos de las multinacionales que comercializan transgénicos, Monsanto: ${ }^{14}$

Cultivos extensivos: Utilizamos la mejora genética tradicional y la biotecnología para producir semillas que se desarrollan como cultivos más fuertes, más resistentes, y que utilizan los recursos naturales de manera más eficiente.

Hortícolas: Combinamos la mejora genética tradicional con técnicas modernas para crear verduras más llenas de vitalidad y sabor que pueden soportar mejor los desafíos de la naturaleza. (nota: las cursivas son nuestras).

Como podemos observar, sutilmente se califica a la agricultura que practicaban nuestros antepasados como "mejora genética tradicional", con lo que indirectamente se está postulando que la biotecnología contemporánea hace lo

\footnotetext{
${ }^{14}$ MONSANTO, Se publica el informe de sostenibilidad de Monsanto para el año 2014. En http://www.monsantoblog.es/se-publica-el-informe-de-sostenibilidad-de-monsanto-para-el-ano-

2014/. Última visita en febrero de 2018.
} 
mismo, solo que con técnicas modernas. Pues bien, esa es la anomalía, que será lo mismo, pero no es igual.

En 2001 unos investigadores consiguieron transferir un gen de una medusa a un mono Rhesus. El gen expresa una proteína que hace fluorescente, no al mono, pero sí a sus células examinadas al microscopio (Chang et al. 2001).

Pues bien, hay una diferencia sustancial entre los productos artificiales, si queremos emplear esa expresión, que ha creado el ser humano a lo largo de la historia, como el maíz o el perro, y el mono Rhesus citado. La interferencia en la dotación genética de los seres vivos, rompiendo las barreras entre las especies, o activando o silenciando genes, es cualitativa y sustancialmente diferente a lo que se ha hecho antes.

Es cierto que quizá nos falte el vocabulario adecuado (el término transgénico u organismo modificado genéticamente también presenta problemas, como analizaremos después) para recoger esas diferencias, pero eso no significa que estas no existan.

No se trata, ni mucho menos, de estar en contra de modificar genéticamente los organismos vivos, ya que estas técnicas pueden favorecer a la especie humana no solo en la mejora de la calidad de vida, sino también en su supervivencia a largo plazo. Ahora bien, es necesario ser conscientes del enorme salto cualitativo que suponen las nuevas tecnologías con respecto al pasado, ya que si no, careceremos de instrumentos para prever y canalizar las consecuencias. Esta reflexión es la que nos conduce al segundo modelo.

\section{Segundo modelo: "biotecnología tradicional (0)”; "biotecnología moderna (1)"}

Los axiomas básicos de las narrativas pertenecientes a este paradigma son los siguientes:

$\left.1^{\circ}\right)$ La biotecnología moderna es sustancialmente diferente a la biotecnología tradicional.

$2^{\circ}$ ) La biotecnología moderna es una disciplina de segundo orden, al servicio de la industria y orientada al mercado en un sistema de economía capitalista.

$3^{\circ}$ ) A los principios tradicionales de la bioética hay que añadirle el principio de precaución.

Pues bien, establecidos estos axiomas, hemos de plantearnos la cuestión de cuándo comenzó la biotecnología a ser un problema. Para comprender qué 
queremos decir, es preciso matizar que esta cuestión no es equivalente a la de cuál es el origen de la biotecnología.

En efecto, el origen de la disciplina que estudiamos se puede situar en varias fechas: en 1919, cuando el ingeniero húngaro Károly Ereki empleó este término por primeva vez en su libro Biotecnología en la producción cárnica y láctea de una gran explotación agropecuaria; en 1953, cuando James Watson y Francis Crick descubrieron la doble hélice del $\mathrm{ADN} ;{ }^{15}$ en 1962, cuando se creó la primera revista científica que incluyó en su título la palabra "biotecnología", en concreto, Biotechnology and Bioengineering (Universidad de Granada ${ }^{16}$ ); en 1973, cuando se clona el primer gen humano, responsable de la insulina; ${ }^{17}$ en 1973, cuando los científicos logran por primera vez transferir ADN de un organismo a otro; ${ }^{18}$ en 1976 , cuando la primera empresa biotecnológica, Genentech, logra expresar proteínas humanas en bacterias. ${ }^{19}$ en 1982, cuando se comercializa la insulina humana; ${ }^{20}$ en 1983 , cuando comienza la biotecnología agrícola con los transgénicos, ${ }^{21}$ etc.

Como podemos constatar, cualquiera de estas fechas, y muchas otras que podríamos recopilar, es buena para situar el nacimiento de la biotecnología. Sin embargo, no nos interesa ese dato, meramente cronológico, sino a partir de qué momento estas investigaciones fueron una fuente de preocupación para las ciencias sociales. Podemos observar la relevancia de la biotecnología contemporánea con el siguiente dato: si incluimos la palabra "biotecnología" en la base de datos del CSIC, la principal en lengua castellana, aparecen más artículos en ciencias sociales (en concreto, 561), que en Ciencia y Tecnología (549 artículos). ${ }^{22}$ Es significativo que los juristas, los filósofos, los humanistas, etc., escriban más sobre la materia que analizamos que los propios científicos.

Pues bien, estimamos que el hiato, el punto de ruptura entre la biotecnología tradicional y la moderna, se produce a comienzos de los años 70, cuando el ser humano aprende a recombinar en un laboratorio ADN de especies diferentes. En

\footnotetext{
${ }^{15}$ BÁRCENA, Alicia, Katz, Jorge, and Morales, César, eds.: Los transgénicos en América latina y el Caribe: un debate abierto. Santiago de Chile, CL: B - CEPAL. 2014.

${ }^{16}$ En http://grados.ugr.es/biotecnologia/, última visita, marzo de 2018

${ }^{17}$ PEÑA (de), Myriam: La biotecnología: fundamentos, aplicaciones y retos. Bogotá, CO: Red Colombia Ciencia y Tecnología. 2006.

${ }^{18}$ DÍAZ, Alberto: Biotecnología en todos lados: en los alimentos, la medicina, la agricultura, la química ... iy esto recién empieza! Buenos Aires, AR: Siglo XXI Editores Argentina, 2014.

${ }^{19}$ Ídem

${ }^{20}$ Ibidem.

${ }^{21}$ Peña, Op. cit.

${ }^{22}$ Fecha de búsqueda, febrero de 2018.
} 
concreto, logra insertar ADN de un virus creado artificialmente en una bacteria presente en el intestino humano (E. Coli).

Como analizaremos posteriormente, este experimento creó bastante alarma en la comunidad científica, debido al temor a que se produjera una pandemia, de ahí que los propios investigadores detuvieran el proyecto y plantearan una moratoria.

Pero es ese momento, principios de los años setenta, cuando el ser humano toma conciencia de que es capaz de interferir en la dotación genética de los seres vivos de una forma completamente diferente a como se había hecho hasta ese momento. A partir de esa fecha nada será igual. Los transgénicos, la clonación, las células madre embrionarias, las células IPS, la vida sintética, la técnica de edición genómica CRISPR, etc., son deudores de esa forma de intervenir en la naturaleza.

De hecho, la definición más completa (y compleja) que podemos hallar sobre la biotecnología moderna está referida precisamente a las técnicas que permiten esa intervención. Así, en el Protocolo de Cartagena sobre Seguridad de la Biotecnología del Convenio sobre la Diversidad Biológica (Montreal, 2000) se establece lo siguiente:

Por Biotecnología moderna se entiende la aplicación de: Técnicas in vitro de ácido nucleico, incluidos el ácido desoxirribonucleico (ADN) recombinante y la inyección directa de ácido nucleico en células u orgánulos, o La fusión de células más allá de la familia taxonómica, que superan las barreras fisiológicas naturales de la reproducción o de la recombinación y que no son técnicas utilizadas en la reproducción y selección tradicionales.

Una definición tan técnica explica que la biotecnología no sea considerada una disciplina propiamente dicha, ${ }^{23}$ sino un campo del conocimiento de segundo nivel al servicio de la industria. De hecho, en muchas universidades, las facultades de biotecnología anuncian a sus alumnos que para poder ser biotecnólogos es una cualidad relevante "tener mentalidad empresarial" (v. gr., la Universidad Francisco de Vitoria), ${ }^{24}$ o que el objetivo de estos estudios es "formar profesionales preparados para la demanda de las empresas biotecnológicas" y fomentar el "espíritu emprendedor" (v. gr., Universidad de Barcelona $^{25}$ ).

Por otro lado, la definición citada explica por qué la biotecnología debe ser tratada, a pesar de las diferencias existentes entre las vacunas, los antibióticos,

\footnotetext{
${ }^{23}$ Peña, Op. cit.

${ }^{24}$ En http://www.ufv.es/grado-en-biotecnologia, última visita en marzo de 2018.

${ }^{25} \mathrm{En}$ http://www.ub.edu/web/ub/es/estudis/oferta_formativa/graus/fitxa/B/G1033/index.html, última visita en marzo de 2018.
} 
los quesos, los yogures, la biodegradación de residuos, los bioinsecticidas, biocombustibles, etc., como un todo.

En efecto, lo que une a productos y técnicas tan diferentes es que la biotecnología contemporánea permite dominar, modificar, controlar, crear o recrear la dotación genética de los seres vivos, incluida la especie humana, sin que sea descartable la creación de otras inexistentes en estos momentos, como sucede con la vida sintética.

Es decir, la biotecnología moderna confiere al ser humano una nueva forma de poder, sin precedentes, tanto sobre la naturaleza como sobre sus semejantes, de ahí que sea una fuente de preocupación en las ciencias sociales y humanidades.

¿Cuál es la función de la bioética en este contexto? Pues bien, en respuesta a esta situación ha aparecido un principio de naturaleza completamente diferente a los cuatro tradicionales, el de precaución.

Este principio nació en realidad para un contexto medioambiental (v. gr. artículo 174 del Tratado CE de Maastricht), pero, por motivos que no son difíciles de intuir, ha acabado recalando en la biotecnología y, en general, en las denominadas tecnologías disruptivas.

Por otra parte, su significado no resulta nada fácil de concretar. Para algunos conlleva que se deben paralizar las investigaciones si no se tiene certeza de qué puede suceder en el futuro. Sin embargo, la vertiente mayoritaria considera que es un principio a invocar cuando se deban adoptar medidas en escenarios de incertidumbre, pero sin detener por ello los avances tecnocientíficos (por ejemplo, en la "Comunicación sobre el recurso al principio de precaución", de la Comisión Europea, COM, 2000, de 1 de febrero).

La realidad es que la legislación de la Unión Europea enarbola este principio con más asiduidad que, por ejemplo, Estados Unidos, lo que se traduce en una mayor prevención hacia los organismos modificados genéticamente. En resumen, el principio de precaución es a la biotecnología lo que el principio de autonomía a la ética clínica, un principio que se trae a colación ante cualquier nuevo avance, técnica, preocupación o escenario hipotético motivado por las nuevas tecnologías, pero cuyos límites últimos son tan difusos como inconmensurables.

¿Qué anomalías podemos observar en el presente modelo?

La primera anomalía es de índole terminológica. Si analizamos los discursos de la mayoría de los agentes que investigan en estos temas, observamos que no definen con claridad qué es un transgénico, qué es un organismo genéticamente modificado, y qué es el resto.

Es más, mientras para unos científicos el género son los transgénicos y el subgénero los organismos modificados genéticamente (por ejemplo, en un libro 
colectivo sobre los cultivos transgénicos en la agricultura latinoamericana ${ }^{26}$ ), para otras instituciones, como la Unión Europea, el género son los organismos modificados genéticamente y los transgénicos son una modalidad dentro de dichos organismos. ${ }^{27} \mathrm{Y}$ estos ejemplos son de la época en que no había aparecido la técnica de edición genómica CRISPR, que sin duda añadirá aún más confusión terminológica.

La segunda es de índole definitoria. Acotar la biotecnología moderna por el tipo de técnicas que emplean los investigadores es realmente absurdo. Sería como intentar definir a un médico por el instrumental que ha ido empleando a lo largo de los últimos tres mil años. Haría falta un libro. Un investigador decía en tono jocoso que la definición que emplea la OCDE para definir la biotecnología "Es como el listado que hay en los menús de los restaurantes chinos". ${ }^{28}$

La tercera crítica es sobre la innecesaria dicotomía sector privado/público que se ha planteado con respecto a los biotecnológos. En efecto, sería inimaginable que una facultad de ciencias políticas planteara a sus alumnos que para poder cursar la carrera resulta necesario matricularse con mentalidad proletaria, sin embargo, nos hemos acostumbrado a que en biotecnología se planteen estos requisitos u objetivos análogos (mentalidad empresarial, espíritu emprendedor), etc., como si los biotecnólogos no pudieran trabajar en el sector público.

La cuarta crítica es de índole más estructural, dado que la biotecnología contemporánea provoca sentimientos agridulces.

Por un lado, forma parte del progreso humano, lo que nos ha permitido los avances que podemos disfrutar hoy día. Se suele olvidar que los dos primeros productos de la biotecnología fueron una bacteria para degradar el petróleo (fracasó, pero la intención es irrenunciable) y la insulina, que es un transgénico. Abogar por prohibir la biotecnología de una región o un país sería como proponer la expulsión de los diabéticos. No podemos renunciar a un campo del conocimiento tan prometedor.

\footnotetext{
${ }^{26}$ AAA.VV.: Cultivos transgénicos para la agricultura latinoamericana. México, D.F., MX: FCE Fondo de Cultura Económica, 2008.

${ }^{27}$ Así, podemos leer en la propia página web de la administración norteamericana la siguiente comparación: "It is these products that many people refer as 'genetically engineered foods'. The European Commission refers to these foods as Genetically Modified Organisms. The United States uses the term genetic modification to refer to all forms of breeding, both modern, i. e., genetic engineering, and conventional" En US Department of Health \& Human Services Administration. https://www.fda.gov/Food/IngredientsPackagingLabeling/GEPlants/ucm461805.htm. Última visita en marzo de 2018.

${ }^{28}$ MILLERH. I.: "Biotech's defining moments.” Trends in Biotechnology, 25(2), 2007, pp. 56-59,
} 
Y por otro, el nacimiento de la moderna biotecnología está unido a la aparición de las multinacionales, que con su inigualable poder económico pueden comprar voluntades y corromper instituciones. Así, a la vez que aparecía la insulina se creaba la primera empresa biotecnológica que la comercializaba, Genentech. Y sucedió esto:

En 1987, aprovechando una de las tantas crisis argentinas, la empresa Eli Lilly, al no conseguir el precio comercial de la insulina que solicitaba, decidió dejar de producirla localmente y abandonar el país. Pero, ¿Y los enfermos? ${ }^{29}$

El 17 de mayo de 2016 la Unión Europea publicó un informe donde, tras veinte años de estudios, se había llegado a la conclusión de que los transgénicos eran seguros para la salud. Dos días después nos enterábamos por la prensa de que la gigante multinacional alemana Bayern había comprado Monsanto, principal productora mundial de transgénicos. Sin caer en teorías conspiratorias, resulta difícil no intuir una relación entre ambos hechos (con total independencia de que los transgénicos puedan ser seguros para la salud humana).

Por último, la aparición de la biotecnología moderna está unida al establecimiento de una moratoria científica (Asilomar, 1975), con todo lo que tiene de grandeza (sentido de responsabilidad de la comunidad científica) y de desasosiego (se planteaban qué probabilidad había de una epidemia). Y es esta la ambivalencia en la que se debemos situar el segundo paradigma que hemos analizado.

\section{Tercer modelo: "biotecnología tradicional (1)”; "biotecnología moderna (0)"}

El grafismo 1-0 subraya que lo relevante es la biotecnología tradicional, de ahí el (1), con el matiz de que ni siquiera se emplearía el término biotecnología, sino el de agricultura tradicional, mientras que las connotaciones negativas serían atribuidas a la biotecnología moderna, (0). Los axiomas básicos de las narrativas pertenecientes a este paradigma son los siguientes: $1^{\circ}$ ) La biotecnología moderna es un instrumento del neoliberalismo capitalista $;^{30} 2^{\circ}$ ) La biotecnología moderna

\footnotetext{
${ }^{29}$ DÍAZ, Alberto (2014): Biotecnología en todos lados: en los alimentos, la medicina, la agricultura, la química ... iy esto recién empieza! Buenos Aires, AR: Siglo XXI Editores Argentina, 2014.

30 "La revolución de la biotecnología a partir de los años noventa (...) estuvo superimpuesta con las reformas realizadas bajo el ímpetu del globalismo neoliberal (...) La biotecnología se ha convertido en la forma tecnológica principal en la agricultura desde la reforma neoliberal del capitalismo a mediados de los años ochenta del siglo XX. La conjunción de neoliberalismo y biotecnología agrícola es lo que aquí llamamos la 'dieta neoliberal'." OTERO, Gerardo: Introducción: crisis alimentaria, dieta neoliberal y biotecnología. La dieta neoliberal: globalización y biotecnología agrícola en las Américas. México, D.F., MX: Editorial Miguel Ángel Porrúa, 2014.
} 
cosifica la naturaleza; $3^{\circ}$ ) La biotecnología moderna es un instrumento del patriarcado; $4^{\circ}$ ) La biotecnología moderna es inmoral en sí misma.

El vocabulario constaría de dos campos semánticos. El primero estaría compuesto de términos con connotaciones positivas para este paradigma, con expresiones como agricultura tradicional, agroecológico; comida orgánica; desarrollo sostenible; multiculturalismo, glocalización (actúa globalmente, piensa localmente), justicia social, campesinado, indigenismo, ecofeminismo, etc. Y el segundo campo estaría compuesto por términos o expresiones con connotaciones negativas, como transgénico, semillas terminator, capitalismo, neoliberalismo, multinacionales, biotecnología, patriarcado, etnocentrismo, etc.

Podemos hallar numerosas publicaciones con imputaciones hacia la biotecnología moderna, pero no una definición exacta de qué es, desde esta perspectiva, la disciplina. Pues bien, tomando como referencia el vocabulario comentado, nos atreveríamos a sostener que los defensores del presente modelo definen tácitamente la biotecnología de la siguiente forma:

Es el instrumento del capitalismo neoliberal, patriarcal y occidental, para cosificar a los seres vivos, incluida la especie humana.

¿Qué función juegan los principios de la bioética en este paradigma? El peso estaría en el principio de justicia, entendida en el sentido de "justicia social" (colectivización, redistribución, no alienación, etc.). Y probablemente es esta concepción de la justicia la que ha dado lugar al principio de soberanía alimentaria, principio que condensa los valores de quienes abogan por este modelo.

¿Qué anomalías podemos hallar en el presente modelo?

La principal anomalía que podemos hallar en este paradigma es la errónea identificación de los "transgénicos" u "organismos modificados genéticamente" con el neoliberalismo capitalista. En efecto, mediante un paradójico proceso de metonimia, los biotecnólogos se han transmutado en el equivalente al hombre blanco, burgués, de alto nivel económico, cristiano protestante, arquetipo del colonialismo y el imperialismo. Se pueden observar las contradicciones de esta injustificada imputación en las corrientes que apoyan la soberanía alimentaria.

El marxismo nunca fue ecologista. La unidad de interés del discurso comunista era el proletariado. Había que mejorar las condiciones de vida de la clase obrera, y el medio ambiente, los seres vivos no humanos, eran tan instrumentales como la hoz y el martillo de la bandera comunista. El lema marxista "La tecnología permitiría la reafirmación del hombre como `ser 
genérico'" abogaba, entre otras cosas, por la ciencia como medio de desalienación de la clase trabajadora. ${ }^{31}$

De hecho, la primera norma de envergadura en la Rusia comunista de rango equivalente a las occidentales, de 1918, llevaba por título "Declaración de los Derechos del Pueblo Trabajador y Explotado", y es fácil imaginar cuán lejos estaban las preocupaciones ecologistas en su articulado. Colectivizaba los recursos naturales, pero no se establecía ninguna protección con respecto al medio ambiente. La Constitución de 1924, que crea la URSS, no contenía referencia alguna sobre el medio ambiente. La Constitución soviética de 1936, en su artículo 4, estableció que la base económica de la URSS era el sistema socialista de economía, basado en la propiedad socialista de los instrumentos y medios de producción, "afirmados como resultado de la supresión del sistema capitalista de economía (...)". El artículo 6 colectivizaba los recursos naturales y el 14.q atribuyó a la Administración del Estado la competencia para "establecer los principios básicos del usufructo de la tierra, del subsuelo, de los bosques y de las aguas". En el artículo 118 hay una referencia interesante al "crecimiento constante de las fuerzas productivas de la sociedad soviética" que muestra su verdadero objetivo: el crecimiento económico. Lo que queremos resaltar es que no se estableció ninguna referencia a la protección del medio ambiente. Es más, hasta la Constitución de la URSS de 1977, pocos años antes de su hundimiento, no se establece un artículo específico para la protección de la naturaleza, en concreto, en el art. 67: "Los ciudadanos de la URSS tienen el deber de cuidar la naturaleza y proteger sus riquezas". El artículo 147 completaba esta obligación, atribuyendo a los soviets locales el deber de proteger la naturaleza. La realidad es que la expresión "protección del medio ambiente" no es una preocupación en el ámbito soviético hasta 1988, justo un año antes de que se hunda la Unión Soviética, y en el contexto de la catástrofe nuclear de Chernóbil. De hecho, es Gorbachov quien cita esta preocupación medioambiental en su último discurso ante el Soviet Supremo. ${ }^{32}$

En el caso de la Cuba castrista todavía es menos evidente esta protección del medio ambiente. Así, el artículo 58 de la Ley Fundamental de Cuba, de 1959 establecía la obligación del Estado de proteger los "lugares notables por su belleza natural”, sin más referencias, y la Constitución cubana de 1976, en una fecha tan cercana como los años setenta, y a diferencia de su homóloga soviética,

\footnotetext{
${ }^{31}$ LYNCH, Enrique: reseña a Blumenger, "Historia del espíritu de la técnica", Traducción de Pedro Madrigal, Pre-Textos, Valencia, 2013. El País, febrero de 2014.

${ }^{32}$ GORBACHOV, Mijail, Informe presentado en el duodécimo periodo extraordinario de sesiones del Soviet Supremo de la URSS de la undécima legislatura. 29 de noviembre de 1988.
} 
no establece ninguna referencia de protección al medio ambiente. En contraste, la Constitución española de 1978, que no es un precisamente un dechado de espíritu ecologista, sí establece una referencia expresa a esta temática en su artículo 45.

La contradicción que supone que gran parte de los movimientos marxistas contemporáneos se opongan a los transgénicos en sí mismos (no solo a las multinacionales que los comercializan, sino a la tecnología en sí misma), se puede observar con toda su crudeza en la propuesta que efectuó en 1990, en Andalucía, la coalición Izquierda Unida, dominada mayoritariamente por el Partido Comunista. En efecto, en dicha fecha IU propuso en el parlamento andaluz que se preparara al campesinado para receptar las nuevas metodologías procedentes de la biotecnología, algo por otra parte coherente con la trayectoria histórica del marxismo: mejorar las condiciones de vida del proletariado y el campesinado. ${ }^{33}$ Pues bien, poco más de veinte años después, esa mismo partido político propuso, también ante dicho parlamento, que se prohibieran los transgénicos en suelo andaluz. ${ }^{34}$

¿A qué se debe el giro "ecologista" del marxismo? Entre 1989 y 1991 se hunde la URSS y desaparece el muro de Berlín. El marxismo occidental contempla con estupor cómo el comunismo se ha hundido solo y ha de enfrentarse a la cruda realidad del estalinismo, de Pol Pot en Camboya, o la oportunista reconversión de China en un capitalismo de Estado. Pues bien, la sustitución de la lógica de la Guerra Fría (capitalismo versus comunismo) por la lógica de la Globalización (extensión por el planeta del modelo liberal occidental

\footnotetext{
33 "El nivel de tecnología medio de la agricultura andaluza en relación a estas técnicas clásicas es suficiente. desde luego; sin embargo, estamos asistiendo en la actualidad a un segundo proceso de renovación tecnológica en la agricultura que viene de la mano de la biotecnología. Me refiero a técnicas nuevas de producción, por ejemplo, por reproducción asexual en tubos de ensayo, de árboles y de plantas que el producirlas en la naturaleza a partir de la semilla cuesta muchísimo más tiempo y garantiza una menor homogeneidad; se trata de técnicas también que pueden mejorar la resistencia a las inclemencias del tiempo o de los agentes bióticos sin dañar el medio ambiente". MEDINA PRECIOSO, Grupo parlamentario de IU, Proposición no de Ley sobre valoración de personal en investigación agraria, 27 de marzo de 1990, p. 6.654.

${ }^{34}$ Propuesta de Izquierda Unida (Partido Comunista y otros).

"Por eso, en esta proposición les planteamos que este Parlamento inste al Gobierno de Andalucía para que, (...) se prohíban los ensayos experimentales en cultivos transgénicos en el territorio andaluz, haciendo especial hincapié en el maíz transgénico NK 603 y en el trigo transgénico. También consideramos necesario que se prohíba el cultivo del maíz MON 810 y la patata Amflora en todo el territorio andaluz. Que avancemos en un corto, medio plazo, largo plazo, se suspendan las importaciones de materias primas de alimentos transgénicos, principalmente la soja y el maíz para alimentación animal." QUINTANA CAMPOS, Diario de Sesiones del Parlamento de Andalucía, $\mathrm{n}^{\mathbf{o}}$ 51, IX Legislatura, 26 de septiembre de 2013, p. 105.
} 
y su modo de vida -Huntington, Fukuyama-) es lo que lleva a la narrativa marxista a identificar esta con el capitalismo neoliberal. Por ese motivo, sustituyen el discurso de la revolución proletaria mundial, que ya no es viable, por el discurso ecologista, al considerar que este ecologismo es una forma de lucha contra una globalización que consideran neoliberal.

La biotecnología ha tenido la mala suerte de aparecer en el lugar equivocado en la fecha equivocada. En efecto, en 1994 comienzan a comercializarse los transgénicos. Pues bien, el hecho de que esta comercialización la llevara a cabo una empresa que después adquirió la multinacional norteamericana Monsanto, a la que para más inri se identifica con el tristemente famoso agente naranja de la guerra del Vietnam, ha provocado que la izquierda marxista posterior a la caída del muro de Berlín identifique a los transgénicos, no ya con las multinacionales, sino con el neoliberalismo mismo, reconvirtiendo a los biotecnólogos en el equivalente a los brokers de Wall Street. Resulta razonable pensar, a la luz de los textos constitucionales soviéticos, que si la URSS hubiese dispuesto de esta tecnología, habría competido con EEUU también en el terreno de los transgénicos, sin que nadie hubiese visto esto como una herejía burguesa. Por ese motivo resulta tan desconcertante que el marxismo contemporáneo mantenga un duro mano a mano con la iglesia católica a la hora de emprenderla a golpes contra la ciencia y la tecnología: esta contra la reproducción asistida y la investigación en células madre embrionarias, y aquel contra los transgénicos.

Algo similar ha sucedido con el ecofeminismo. En consonancia con el panteísmo oriental de Vandana Shiva, este tipo de discursos sacraliza la naturaleza, proceso de deificación que ha sido mimetizado por el ecofeminismo occidental. El resultado de esta adaptación narrativa es que se identifica a la mujer con la naturaleza, a la que se idealiza; al hombre, con la cultura, entendiendo aquí cultura como modelo capitalista/ occidental/ depredador/ neoliberal/colonizador; y a la biotecnología, como el último juguete de la ciencia occidental voraz y depredadora que pretende domeñar la naturaleza.

Pues bien, este proceso de simplificaciones y mistificaciones acarrea graves perjuicios, entre otros, precisamente a la mujer campesina. Como sostiene la propia FAO (2011), ${ }^{35}$ para poder igualar las condiciones de vida de la mujer campesina frente al hombre es necesario romper lo que denominan la "brecha tecnológica", esto es, recurrir a la tecnología más avanzada, lo que incluye los transgénicos.

\footnotetext{
${ }^{35}$ RANEY, Terri; LOUDER, Sarah, and GHANEM, Hafez: El estado mundial de la agricultura y la alimentación. Roma, IT: D - FAO. 2011.
} 
Por decirlo de otra forma, los organismos modificados genéticamente no son en sí mismos antifeministas (basta recordar la historia del maíz o del perro) ni enemigos de la clase obrera. Otra cosa es el neoliberalismo capitalista, que con su imparable proceso de privatizaciones y mercantilización de lo humano monopoliza en estos momentos la tecnociencia. Pero no es legítimo imputar a la biotecnología en sí misma las deplorables condiciones de vida del campesinado, incluidas las mujeres, en tantos lugares. Más bien al contrario, es precisamente la tecnología la que, siguiendo el antaño, y hoy olvidado, discurso marxista basado en el racionalismo y no en el esoterismo, puede mejorar las condiciones de vida de la humanidad.

Por último, el discurso indigenista tampoco está exento de contradicciones. Si leemos la constitución boliviana, paradigma del indigenismo, observamos constantes referencias a la naturaleza (art. 403), a la convivencia armónica entre los seres humanos y esta, etc. En consonancia con este espíritu, el artículo 405 prohíbe la producción e importación de transgénicos.

Sin embargo, un poco más abajo, en el artículo 409, se establece que "La producción, importación y comercialización de transgénicos será regulada por ley." Es decir, el Estado arquetípico de los movimientos indigenistas prevé expresamente que ese mismo Estado, panteísta y respetuoso con la naturaleza, se reserva el derecho a producir transgénicos cuando lo estime necesario. El hecho de que nadie se tome la molestia de leer la constitución boliviana completa explica estas confusiones.

El resultado de estas narrativas se puede observar en la historia del tristemente famoso arroz dorado. Un grupo de investigadores, altruista y generosamente, modificó genéticamente un tipo de arroz para que pudiera ser consumido por una población especialmente necesitada. No solo era más nutritivo, sino que evitaba millones de casos de ceguera en niños por déficits de la vitamina $\mathrm{A}^{36}$ Greenpeace hizo campaña contra el arroz dorado porque contaminaba la naturaleza. El boicot, que indirectamente ha generado ataques y destrucción de cosechas, logró que este tipo de arroz transgénico no se distribuyera. En 2016, más de cien premios Nobel publicaron una carta colectiva en la que acusaban a Greenpeace de crimen contra la humanidad por su ataque contra los transgénicos en general, y el arroz dorado en particular.

Estas contradicciones son las que están presentes en el modelo que hemos analizado. Si la población sigue creciendo exponencialmente, la tierra cultivable

\footnotetext{
${ }^{36}$ SOBERÓN MAINERO, Francisco Xavier (2005): La ingeniería genética, la nueva biotecnología y la era genómica ( $3^{\mathrm{a}}$ ed.). México, D.F., MX: FCE- Fondo de Cultura Económica.
} 
y los cultivos tradicionales no van a poder dar de comer a tanta gente. ${ }^{37}$ Otra cosa es el modelo económico a escala mundial, pero esto necesitaría una discusión aparte. Por otro lado, si el maíz o el perro se hubieran producido de forma consciente en un laboratorio en vez de crearlo de forma inconsciente a lo largo de miles de años, ¿consideraríamos que el maíz natural o el perro son agresiones ecocidas contra la naturaleza, en concreto, contra el lobo o el teosinte, de donde proceden?

Además, la intrahistoria del vocabulario que emplea el paradigma que analizamos tampoco es que ayude mucho en el necesario proceso de clarificación de conceptos e ideas. Cuando se califica un alimento como "orgánico" se está atribuyendo a dicho alimento la cualidad de producto natural, prístino, incontaminado, puro e inmaculado. Sin embargo, "orgánico" significa estrictamente que tiene como componente el carbono (DRAE), y se suele olvidar que el agua no es un compuesto "orgánico"; que el plástico puede ser también un compuesto "orgánico", aunque se cree artificialmente; que un transgénico puede ser tan orgánico como los organismos no transgénicos (bastaría con que tuviera, y en efecto, lo tienen, carbono); y que el creador de la célebre expresión "comida orgánica", el filósofo Rudolf Steiner, tan alabado en los libros de agroecologismo, ${ }^{38}$ publicó obras con títulos como El pensamiento intuitivo como sendero espiritual (1886); El cristianismo como hecho místico (1902); Teosofía: una introducción a los procesos espirituales en la vida humana y en el cosmos (1904); La ciencia oculta: un bosquejo (1910), alcanzando el éxtasis del esoterismo con el libro Lucifer y Ahrimai. Diez conferencias antroposóficas, que trataba sobre la demonología, el satanismo y el luciferismo. ${ }^{39}$ La famosa encuesta del sociólogo Pardo ("ocho de cada diez españoles opina que los 'tomates ordinarios' no tienen genes, en tanto que los tomates modificados genéticamente, sí" ${ }^{40}$ ) es la consecuencia de este batiburrillo de creencias.

\footnotetext{
${ }^{37}$ BÁRCENA, Alicia, Katz, Jorge, and Morales, César, eds.: Los transgénicos en América latina y el Caribe: un debate abierto. Santiago de Chile, CL: B - CEPAL. 2004.

${ }^{38}$ Así, podemos observar su influencia contemporánea: "El movimiento de la agricultura orgánica internacional data de hace más de 70 años. (...) siendo el austríaco Rudolf Steiner, filósofo y educador, quien en 1924 expresó los principios de una agricultura fundada en un criterio antroposófico. Sus principios están en contra de los excesos de los fertilizantes químicos porque "matan la tierra y a los microorganismos del suelo" y aconseja utilizar "compostas" o abonos preparados con ciertas sustancias vegetales susceptibles de jugar un papel biocatalizador". QUISPE LYMAYLLA, Aníbal: Tecnologías alternativas para la producción de alimentos sanos y nutritivos. México, D.F., MX: Plaza y Valdés, S.A. de C.V., 2007.

${ }^{39}$ Enciclopedia Británica. Voz Rudolf Steiner.

${ }^{40}$ BENITO, E. El País, 31 de julio de 2003.
} 
En resumen, cómo conciliar la justicia social con la ciencia y la tecnología, que precisamente pueden coadyuvar a dicha justicia, sin caer en el pensamiento mágico, es el principal dilema del paradigma que hemos estudiado.

\section{Cuarto modelo: "biotecnología tradicional (0)”; biotecnología moderna (1)”}

El grafismo 0-1 subraya que lo relevante es la biotecnología moderna, de ahí el (1), pero, a diferencia del segundo modelo que estudiamos, se resalta que lo mejor (o peor) está por llegar, ya que la biotecnología está enlazando con otras materias, como la inteligencia artificial o la vida sintética, que suponen un hiato no solo con la biotecnología tradicional, sino con la propia historia de la civilización humana. El "0" subrayaría que nuestra existencia misma es solo una fase de transición hacia un mundo posthumano, cuyo momento inicial, esto es, cuando un ente creado por nosotros nos rebase, denominan "singularidad".

Los axiomas básicos de las narrativas pertenecientes a este paradigma son las siguientes: $1^{\circ}$ ) La tecnología resolverá los problemas sociales, económicos y políticos humanos; $2^{\circ}$ ) La tecnología permitirá que alcancemos la inmortalidad, la eterna juventud, la conciencia virtual, etc.; $3^{\circ}$ ) O, por el contrario, caminamos sin remisión alguna hacia algún apocalipsis tecnológico que acarreará la extinción de la vida.

El mayor problema que constatamos en este tipo de narrativas reside en la dificultad inherente a calibrar el grado de probabilidad, o verosimilitud, de los diferentes escenarios que se nos presentan.

En esencia, las narrativas que podemos situar en este paradigma juegan con la psicología humana, al reproducir los mitos que podemos rastrear en infinidad de relatos del pasado, de ahí que en general se considere poco serio prestarles atención.

Sin embargo, la dicotomía tecnoutopía versus distopía es demasiado simple para valorar lo que está en juego. Para analizar con el suficiente rigor esta temática debemos comenzar por tratar de definir la biotecnología a partir de un comentario efectuado desde la primera línea científica:

La emergencia de tecnologías innovadoras como la inteligencia artificial, la nanotecnología y la biología sintética está borrando las fronteras de nuestra distinción entre la materia viva y la no viva. ${ }^{41}$

${ }^{41}$ DEPLAZES, Amna; HUPPENBAUER, Markus: "Synthetic organism and living machines", Syst Synth Biol, 3, 2009, pp. 55-63. 
Aunque no es propiamente una definición, la reflexión nos resulta útil para lo que queremos mostrar. Hasta ahora, la bioética y la biotecnología llevaban el prefijo "bio" porque su objeto eran los organismos vivos. Nunca nadie previó que algún día íbamos a tener que lidiar con organismos híbridos que no sabemos muy bien si pertenecen al reino de los seres vivos o al de la materia inerte, como sucede con los robots, la biología sintética, la inteligencia artificial o los nuevos materiales. Simplemente carecemos de recursos intelectuales para prever escenarios a medias entre la ciencia ficción, el milenarismo y, todo quede dicho, la estupidez humana.

Las preguntas son muy sencillas, pero no por ello de menor alcance. $\left.1^{\circ}\right)$ ¿Debemos ocuparnos también de esto? O por decirlo de otra forma, debemos juridificar la ciencia ficción, es decir, regular escenarios hipotéticos, improbables, casi imposibles, solo porque lo que está en juego sea, en última instancia, la vida misma; $2^{\circ}$ ) ¿Debemos regular el riesgo existencial, es decir, aquellas situaciones donde el peor escenario posible sea la extinción de la especie humana; $3^{\circ}$ ) Ante este tipo de escenarios, ¿basta con la autorregulación científica, cuyo único instrumento son las moratorias, o debemos ir más allá e intervenir ante el menor atisbo de alarma?

Pues bien, para poder responder, aunque sea parcialmente, a estas preguntas, debemos comenzar por preguntarnos qué es propiamente la ciencia ficción. Para ello debemos distinguir entre: a) ciencia ficción propiamente dicha, que es la que propone la violación de las leyes de la naturaleza (viajar más rápido que la luz; soslayar la entropía, etc.). Las constantes cosmológicas estaban ahí cuando devino la conciencia humana, de forma que no podemos contrariarlas debido a que son reglas inherentes al universo en que vivimos. Es cierto que siempre se puede especular con agujeros de gusano, multiversos, etc., pero debemos partir del apriorismo de que todo no es posible, y que hay reglas fijas, absolutas e inmutables en la física, aunque no sepamos el porqué. En resumen: violar estas reglas es ciencia ficción; b) ciencia ficción impropia. Estaría representada por aquellos escenarios que no violan ninguna ley de la naturaleza (nada impide poblar Marte, por ejemplo), pero que no son viables porque carecemos de la tecnología adecuada para llevarlos a cabo (no disponemos de materiales adecuados para proteger a los astronautas de la radiación solar durante varios meses, por ejemplo, de ahí que no podamos colonizar Marte). La imaginativa mente de Julio Verne explotó precisamente esos escenarios, por eso algunos se han cumplido, no porque el ser humano pueda violar leyes de la naturaleza, sino porque solo era cuestión de tiempo que construyéramos submarinos o viajáramos a la Luna. 
Muchos de los escenarios que podemos analizar en la biotecnología contemporánea pertenecen a esta categoría, a la ciencia ficción impropia. Así, un equipo de varios premios Nobel dirigidos por George Church está intentando crear un ser humano sintético (o sintetizado). Para ello han recaudado cien millones de dólares, de los tres mil que costará el proyecto, y se han dado un plazo de diez años. ${ }^{42}$ Aunque no prevén embarazar a una mujer con un embrión construido íntegramente en un laboratorio, sino emplear las células como modelo para las enfermedades humanas, es obvio que si lo lograran lo cambiarían todo, absolutamente todo. La pregunta es: ¿es posible conseguir algo así con nuestra tecnología actual? ¿Y con la futura? Previamente, George Church había propuesto recuperar a los neandertales clonando su ADN y embarazando a una humana ${ }^{43}$ y también a los mamuts. ${ }^{44}$

Izpisúa dirige un proyecto internacional para lograr que los cerdos puedan generar órganos humanos en su interior. El loable proyecto, que pondría fin a la incertidumbre de los trasplantes, contempla también hipotéticos escenarios que hacen perder el sueño. El propio Izpisúa nos ilustraba sobre el riesgo que supone que células humanizadas se vayan al cerebro del cerdo y este razone; o que acabe en el aparato reproductor y un cerdo con un espermatozoide humanizado preñe a una cerda con un óvulo humanizado, generando un embrión cuyo estatus es mejor no imaginar. ${ }^{45}$

Ante este tipo de posibilidades, ¿debemos intervenir estableciendo reglas apriorísticas para impedir escenarios improbables pero no imposibles? ¿O es mejor simplemente esperar, dado el escaso riesgo de que algo así pueda ser real? De este tipo de preocupaciones deriva el concepto de "riesgo existencial", de Bostrom, ${ }^{46}$ esto es, situaciones en las que la vida en el planeta puede quedar seriamente comprometida.

Ahondando en esta temática, resulta sintomático que entre 2011 y 2014 se hayan creado tres organismos participados por universidades públicas

\footnotetext{
${ }^{42}$ BOECKE, J; CHURCH, G.; HESSEL, A.; KELLEY, N; ARKIN, A.; CAI, Y.; CARLSON, R.; CHAKRAVARTI, A.; CORNISH, V.; HOLT, L.; ISAACS, F.; KUIKEN, T.; LAJOIE M.; LESSOR, T.; LUNSHOF, J.; MAURANO, M.; MITCHELL, L.; RINE J.; ROSSER, S.; SANJANA, N.; SILVER, P.; VALLE, D.; WANG, H.; WAY J.; YANG, L.: "The Genome Project-Write", Science, 8 July, 2016.

${ }^{43}$ CHURCH, George: Regenesis, How Synthetic Biology Will Reinvent Nature and Ourselves. Ed. Regis. 2011.

${ }^{44}$ CHURCH, George: "Volved a la vida", Investigación y Ciencia. Octubre de 2013.

45 IZPISÚA Belmonte, Juan Carlos (2017): "Órganos humanos fabricados dentro de animales", Investigación y Ciencia, enero.

${ }^{46}$ Bostrom, N.: "Existential risks: analyzing human extinction scenarios and related hazards", Journal of evolution and technology 9, 2002.
} 
prestigiosas dirigidos a estudiar única y exclusivamente los "riesgos existenciales": el Fondo Skoll para las Amenazas Globales, el Centro para el Estudio de los Riesgos Existenciales de la Universidad de Cambridge, y el Instituto Riesgos Catastróficos Globales (GCRI). También están proliferando publicaciones bastante agoreras acerca de nuestro futuro inmediato ${ }_{¿ \text { Por qué el }}$ futuro no nos necesita?, del creador de Java, Bill Joy; Nuestra hora final. ¿Será el siglo XXI el último de la humanidad?, del cosmólogo Martin Rees, etc.). Junto al análisis de riesgos sobre los que nada podemos hacer (eventos cosmológicos, básicamente, como que nos arrase la explosión de una supernova cercana), se ponen de manifiesto los riesgos de la tecnociencia contemporánea. Pues bien, en los informes y publicaciones que han emitido estos organismos e investigadores, la biotecnología ocupa un lugar privilegiado.

En 2011, un grupo de investigadores holandeses y otro norteamericano logró, provocando en laboratorio las mutaciones adecuadas, que el virus de la gripe aviar fuese transmisible entre seres humanos. Su objetivo era demostrar que la naturaleza puede provocar algo así de forma espontánea y azarosa, por lo que debemos estar alertas y anticiparnos creando vacunas.

El problema es que el virus de la gripe aviar no se transmite de humanos a humanos, solo de animales a humanos, y cuando nos contagiamos, la tasa de mortalidad es del 60\% (el virus de la gripe española, que mató a 50 millones de personas, tenía una tasa de mortalidad de tan solo el $2 \%$ ). Pues bien, una vez efectuados los experimentos, los investigadores mandaron los resultados a Nature y a Science. La Administración Obama trató de impedir su publicación, pero al final, después de muchos debates, se publicaron. ${ }^{47}$

¿Qué sucede si dicho virus modificado en un laboratorio se escapa? ¿O si alguien reproduce el experimento? ¿Quién decide el nivel de riesgo que hemos de asumir colectivamente? Existe un proyecto denominado iGEM, algo así como el equivalente al "hazlo por ti mismo" del software libre, solo que en la biología sintética. ¿Puede un equipo de estudiantes, por curiosidad, ambición o temeridad, lograr algo como lo que hicieron los holandeses y los norteamericanos? Los investigadores principales sostienen que no, ya que la tecnología necesaria es muy sofisticada. Pero volvemos a la cuestión de la ciencia ficción impropia: ¿qué significa exactamente "tecnología sofisticada"?, ¿por cuánto tiempo es sofisticada?, ¿es sofisticada para China, Rusia, etc.?

Esto nos lleva a la cuestión de la autorregulación científica. Como hemos comentado anteriormente, a principios de los años setenta del siglo pasado se

${ }^{47}$ LÓPEZ BARONI, Manuel Jesús: "Implicaciones éticas de las investigaciones con virus: el Principio de Colaboración Global”, Revista Bioética y Derecho, 2015, pp. 37-52. 
comenzaron los experimentos con ADN recombinante. Consistieron en infectar una bacteria presente en el organismo humano, E. Coli, con "un virus creado artificialmente, a partir de virus de E. coli y del virus SV 40, un virus de los simios". ${ }^{48}$ Pues bien, la propia comunidad científica suspendió el experimento por temor a que se provocara una pandemia oncológica. ${ }^{49}$ Por este motivo, se convocó la famosa Conferencia de Asilomar (1975), donde se acordó una moratoria de seis meses hasta que se demostrara que no había riesgo para la humanidad.

Asilomar ha quedado como un símbolo de la autorregulación científica, ya que, sin requerimiento alguno por parte de las autoridades públicas, los propios científicos valoraron de forma sensata, prudente y responsable el alcance de sus investigaciones. Es el llamado "espíritu de Asilomar".

Pues bien, durante la crisis de la gripe aviar que hemos comentado, mientras se debatía si Nature y Science publicaban cuáles eran las mutaciones necesarias para hacer transmisible entre los seres humanos el virus de la gripe aviar, la propia comunidad científica acordó, eso sí, esta vez bajo presión de las autoridades norteamericanas, una moratoria de un año. Cuando finalmente se acordó publicar los resultados (probablemente bajo presión china, la principal afectada por este virus), se suspendió la moratoria.

El principal problema de la moratoria científica es que se carece de instrumentos jurídicos para imponerla a la comunidad científica. ¿Quién va a obligar a China a cumplir con una moratoria decretada por Occidente? ¿Y qué ocurre si alguien no está de acuerdo y prosigue con las investigaciones?

En este contexto, ¿qué papel puede jugar la bioética? Pues bien, los cuatro famosos principios tradicionalmente invocados difícilmente juegan papel alguno. $\mathrm{Si}$ acaso, que en estos contextos se viola el principio de autonomía, esto es, la autonomía de las generaciones futuras que no pueden dar su consentimiento informado porque nunca van a ver la luz...

El principio que se suele invocar en estos escenarios es el principio de responsabilidad, de Jonas, basado en lo que denomina "una heurística del temor". Ahora bien, Jonas también es empleado por los tecnófobos para justificar la paralización de cualquier avance científico. Se podría decir que nos hallamos en esa tesitura: seguir avanzando, con los riesgos, incluidos los existenciales, que ello conlleva; o proponer una moratoria indefinida, que, dada la superpoblación y sobreexplotación de los recursos contemporánea, tampoco es que sea una opción exenta de riesgos existenciales.

\footnotetext{
${ }^{48}$ ALONSO, Luis: Investigación y ciencia. Noviembre de 2014.

49 Ídem.
} 
Entre uno y otro discurso hemos de situar nuestros actos, de forma que ante este tipo de escenarios tan perturbadores tratemos de acompañar el progreso científico al mismo tiempo que nos adelantamos a las consecuencias éticas, sociales o políticas del mismo. Hallar el equilibrio adecuado entre la prudencia y el histerismo será uno de los mayores retos de la humanidad en las próximas décadas.

\section{Conclusioones}

La biotecnología, junto a la nanotecnología, la biología sintética, la inteligencia artificial o los big data, forma parte de las denominadas tecnologías disruptivas, debido, entre otros factores, a los perturbadores interrogantes que generan sus progresos. Parafraseando a Ricoeur, podríamos agruparlas bajo la expresión tecnologías de la sospecha, por su capacidad para modificar estructuralmente el futuro de la civilización humana, incluidos nuestros valores, vertebración social y relación con el ecosistema, del que formamos parte. Pues bien, teniendo presente la relevancia de este campo del conocimiento, podemos estar en condiciones de valorar los cuatro modelos analizados.

Del primer modelo podríamos destacar como aportación positiva que nos muestra el escaso rigor con que se emplean términos, conceptos o ideas como "natural" y "artificial", además del desconocimiento social que suele haber sobre el origen de la mayor parte de los alimentos que consumimos. En su debe podemos reseñar que no permite tomar conciencia de las sustanciales diferencias que hay entre la biotecnología tradicional y la contemporánea.

Del segundo modelo podríamos destacar como aspecto positivo que permite tomar conciencia de la existencia de un hiato claro, nítido, entre la biotecnología tradicional y la contemporánea, lo que nos invita a ser tomar medidas sobre los riesgos sin renunciar a los beneficios de la biotecnología. En su debe podemos situar la orientación meramente utilitarista de la biotecnología, como disciplina subordinada a la industria, además del creciente poder de las multinacionales en este campo del conocimiento.

Del tercer modelo podríamos destacar la lucha contra el neoliberalismo, lo que nos obliga a examinar con sumo cuidado todo lo referente a las patentes, al monopolio, a la concentración de capital y al poder fáctico que constituyen las multinacionales. En su debe podemos reseñar el vocabulario, más cercano al pensamiento mágico que a la ciencia, y la creación de injustificados anatemas sobre la biotecnología. 
Y del cuarto modelo podríamos destacar que nos obliga a preparar escenarios imprevisibles, pero no imposibles, máxime si tenemos en cuenta el incremento exponencial de los avances científicos. En su debe podemos reseñar la escasa seriedad con que se tratan estas temáticas, lo que paradójicamente relativiza y frivoliza la gravedad de estos escenarios.

En conclusión, es necesario deslindar a la biotecnología contemporánea del neoliberalismo capitalista, que actualmente la monopoliza, cuando no la fagocita. Pero también del esoterismo. Es más, probablemente habría que abogar por que la biotecnología se publifique, tal y como sucede con otros sectores de la economía o de la sociedad. Si los riesgos los asumimos, queramos o no, todos, ¿por qué no socializar también los beneficios?

\section{Bibliografía}

AAA.VV.: Cultivos transgénicos para la agricultura latinoamericana. México, D.F., MX: FCE - Fondo de Cultura Económica. 2008.

AGUILAR, Susana; JORDAN, Andrew J.: "Principio de precaución, políticas públicas y riesgo", en Política y Sociedad, Vol 40, núm. 3, 2003, pp. 61-79.

ALONSO, Luis: Investigación y ciencia. Noviembre de 2014.

ALTIERI, Miguel, Los mitos de la biotecnología agrícola: algunas consideraciones éticas. Córdoba, AR: El Cid, Editor, 2009.

BÁRCENA, Alicia, Katz, Jorge, and Morales, César, eds.: Los transgénicos en América latina y el Caribe: un debate abierto. Santiago de Chile, CL: B CEPAL, 2004.

BEADLE, George: "El origen del maíz", Investigación y Ciencia, $\mathrm{n}^{\circ}$ 42, marzo, 1980.

BOECKE, J; CHURCH, G.; HESSEL, A.; KELLEY, N; ARKIN, A.; CAI, Y.; CARLSON, R.; CHAKRAVARTI, A.; CORNISH, V.; HOLT, L.; ISAACS, F.; KUIKEN, T.; LAJOIE M.; LESSOR, T.; LUNSHOF, J.; MAURANO, M.; MITCHELL, L.; RINE J.; ROSSER, S.; SANJANA, N.; SILVER, P.; VALLE, D.; WANG, H.; WAY J.; YANG, L.: "The Genome Project-Write", Science, 8 July, 2016.

BOSTROM, N.: "Existential risks: analyzing human extinction scenarios and related hazards", Journal of evolution and technology 9, 2002.

CAPELL CAPELL: Catedrática del Departamento de Producción Vegetal y Ciencia Forestal de la Universidad de Lleida, e investigadora de agrotecnio. Diario de Sesiones del Congreso de los Diputados. Comisiones. Núm. 460, 19 de noviembre, 2013, p.13. 
CHAN, W.S; CHONG, K,Y; MARTINOVICH, C; SIMERLY C; SCHATTEN, G.: "Transgenic Monkesys Produced by Retroviral Gene Transfer into Mature Oocytes", Science, 12 Jan, 2001, pp 309-312.

CHURCH, George: Regenesis, How Synthetic Biology Will Reinvent Nature and Ourselves. 2011.

CHURCH, George: "Volved a la vida", Investigación y Ciencia. Octubre de 2013.

DEPLAZES, Amna; HUPPENBAUER, Markus: "Synthetic organism and living machines", Syst Synth Biol, 3, 2009, pp. 55-63.

DÍAZ, Alberto: Biotecnología en todos lados: en los alimentos, la medicina, la agricultura, la química ... iy esto recién empieza! Buenos Aires, AR: Siglo XXI Editores Argentina, 2014.

FREEDMAN, AH, Gronau I, Schweizer RM, Ortega-Del Vecchyo D, Han E, Silva PM, et al.: "Genome Sequencing Highlights the Dynamic Early History of Dogs." PLoS Genet 10(1), 2014.

HALL: "CRISPR llega a los cultivos", Investigación y Ciencia, septiembre de 2016.

IZPISÚA Belmonte, Juan Carlos: "Órganos humanos fabricados dentro de animales", Investigación y Ciencia, enero, 2017.

JONAS: El principio de responsabilidad, (título original Das Prinzip Verantwortung, Inserl Verlag, traducción de Javier Fernández Retenaga, Empresa Editorial Herder SA, Barcelona, 1995.

KATO YAMAKAKE, Takeo Ángel: ¿Cómo y dónde se originó el maíz? Investigación y Ciencia, $\mathrm{n}^{\circ}$ 347, 2005.

LAURENT, A. F. Frantz, Victoria E. Mullin, Maud Pionnier-Capitan, Ophélie Lebrasseur, Morgane Ollivier, Angela Perri, Anna Linderholm, Valeria Mattiangeli, Matthew D. Teasdale, Evangelos A. Dimopoulos, Anne Tresset, Marilyne Duffraisse, Finbar McCormick, László Bartosiewicz, Erika Gál, Éva A. Nyerges, Mikhail V. Sablin, Stéphanie Bréhard, Marjan Mashkour, Adrian Bălăşescu, Benjamin Gillet, Sandrine Hughes, Olivier Chassaing, Christophe Hitte, Jean-Denis Vigne, Keith Dobney, Catherine Hänni, Daniel G. Bradley, Greger Larson, (2016): "Genomic and archaeological evidence suggest a dual origin of domestic dogs", Science, 2003 Jun: pp. 1228-1231.

LÓPEZ BARONI, Manuel Jesús: "Implicaciones éticas de las investigaciones con virus: el Principio de Colaboración Global”, Revista Bioética y Derecho, 2015, pp. 37-52.

LUJÁN, Jose Luis, y LÓPEZ CEREZO, José: "La dimensión social de la tecnología y el principio de precaución”, en Política y Sociedad, Vol. 40, núm. 3, 2003, pp. 53-56. 
LYNCH, Enrique: reseña a Blumenger, "Historia del espíritu de la técnica", Traducción de Pedro Madrigal, Pre-Textos, Valencia, 2013. El País, febrero. 2014.

MANGELSDORF, Paul: “El origen del maíz”, Investigación y Ciencia, 121, Octubre, 1986.

MILLERH. I: "Biotech's defining moments." Trends in Biotechnology, 25(2), 2007, pp. 56-59.

MORELL, Virginia: "Evolución del lobo al perro", Investigación y Ciencia. Septiembre, 2015.

OTERO, Gerardo, Introducción: crisis alimentaria, dieta neoliberal y biotecnología. La dieta neoliberal: globalización y biotecnología agrícola en las Américas. México, D.F., MX: Editorial Miguel Ángel Porrúa, 2014.

PEÑA (de), Myriam: La biotecnología: fundamentos, aplicaciones y retos. Bogotá, CO: Red Colombia Ciencia y Tecnología, 2006.

QUISPE LYMAYLLA, Aníbal: Tecnologías alternativas para la producción de alimentos sanos y nutritivos. México, D.F., MX: Plaza y Valdés, S.A. de C.V., 2007.

RAMÍREZ, Manuel Álvaro: "Lineamientos para seguridad alimentaria: retos y perspectivas", Economía y Desarrollo, marzo 2002, vol. 1, n 1.

RAMOS TORRES, Ramón: "Al hilo de la precaución: Jonas y Luchmann sobre la crisis ecológica", en Política y Sociedad, Vol. 40, núm. 3, 2003, pp. 23-52.

SERRATOS HERNÁNDEZ: El origen y la diversidad del maíz en el continente americano, Greenpeace, 2009.

TRUT, Lyudmila\&DUGATKIN, Lee Alan: "Zorros convertidos en perros". Investigación y Ciencia, $\mathrm{n}^{\circ}$ 490, julio de 2017.

VILÁ, Carles: "Domesticación del perro. Relaciones entre perro y lobo", Investigación y Ciencia, marzo, 1999.

SOBERÓN MAINERO, Francisco Xavier: La ingeniería genética, la nueva biotecnología y la era genómica ( $3^{\mathrm{a}}$ ed.). México, D.F., MX: FCE- Fondo de Cultura Económica, 2005. 